\title{
AIRBORNE TECHNOLOGIES FOR DISASTER MANAGEMENT
}

\author{
Jürgen Schulz
}

Hansa Luftbild AG, 48147 Münster, Germany, schulz@ hansaluftbild.de

KEY WORDS: airborne remote sensing, flooding, urban flash floods, bark beetle

\section{ABSTRACT:}

Currently, satellite-based systems and UAVs are very popular in the investigation of natural disasters. Both systems have their justification and advantages - but one should not forget the airborne remote sensing technology. The presentation shows with three examples very clearly how airborne remote sensing is still making great progress and in many cases represents the optimal method of data acquisition.

The airborne detection of forest damages (especially currently the bark beetle in spruce stands) can determine the pest attack using CIR aerial images in combination with ALS and hyperspectral systems - down to the individual tree. Large forest areas of $100 \mathrm{sqkm}$ and more can be recorded from planes on one day (100 sqkm with $10 \mathrm{~cm}$ GSD on one day).

Flood events - such as on the Elbe in 2013 - were recorded by many satellites. However, many evaluations require highresolution data $(\mathrm{GSD} 10 \mathrm{~cm})$, e.g. to clarify insurance claims. Here the aircraft system, which was able to fly below the cloud cover and was constantly flying at the height level of the flood peak, proved to be unbeatable.

The phenomenon of urban flash floods is one of the consequences of climate change. Cities are not in a position to cope with the water masses of extreme rain events and so are confronted with major damages. In Germany, a number of cities are already preparing to manage short-term but extreme water masses. The complicated hydrographic and hydraulic calculations and simulations require above all one thing - a precise data basis. This involves, for example, the height of kerbstones and the recording of every gully and every obstacle. Such city-wide data can only be collected effectively by photogrammetric analysis of aerial photography (GSD 5 to $10 \mathrm{~cm}$ ).

\section{INTRODUCTION}

Airborne remote sensing has a long tradition in which Hansa Luftbild played a decisive role. Founded in 1923, Hansa Luftbild quickly became the largest aerial

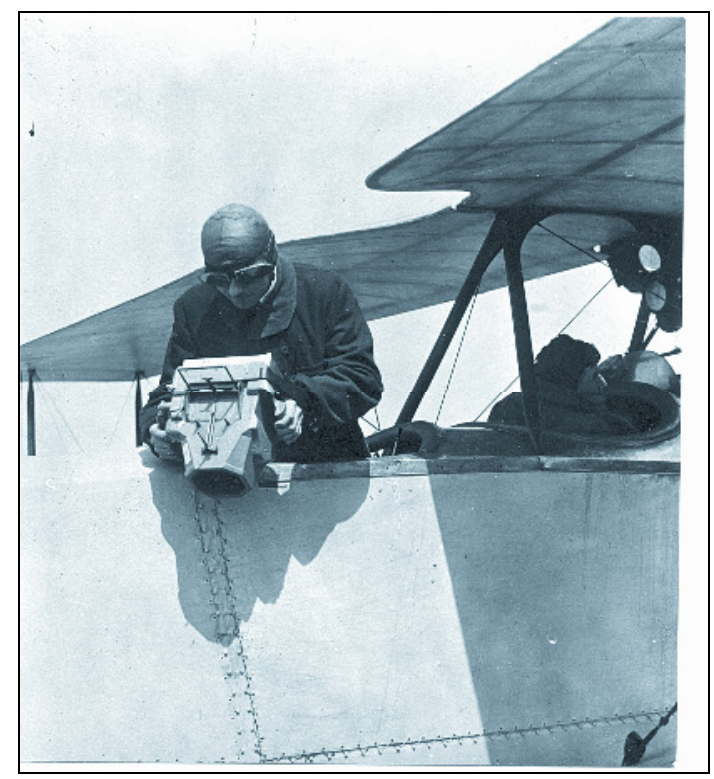

Fig 1: Hansa Luftbild Photograph

Max Bundermann

Today, Hansa Luftbild is a leading European company in the fields of airborne remote sensing, photogrammetry, laser scanning and geodata processing - however, due to technical developments and the competitive situation, this position has to be constantly redefined.

According to an increasing number of technical articles, airborne remote sensing will soon be replaced by satellite data and drones. In fact, there is enormous technical photography company in the world, flying through Antarctica, Greenland, Afghanistan, China and Peru. A mountain range in the Antarctic is still named after the pilot of Hansa Luftbild "Bundermann Chain".

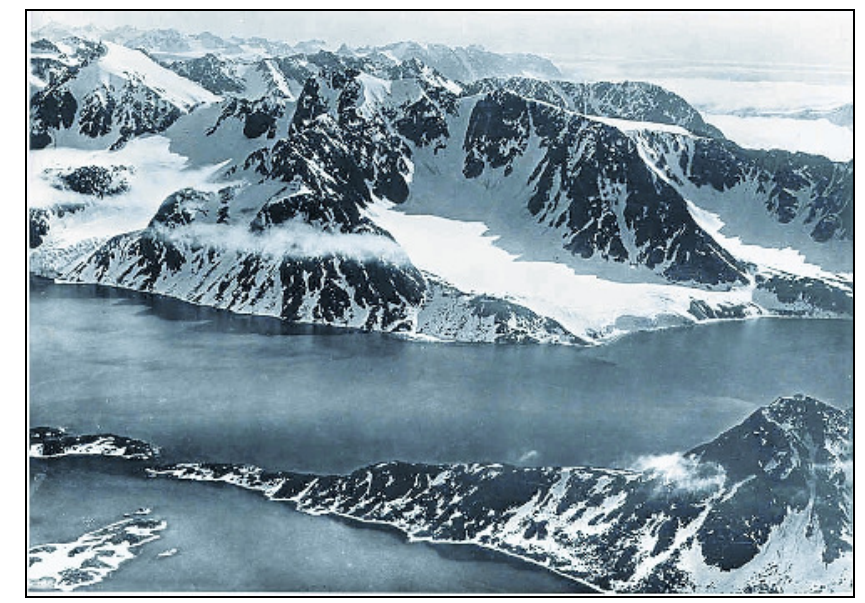

Fig 2: Bundermann Chain (Antarktis)

progress in satellites and drones, so such an assessment seems realistic. But is the importance of airborne geodata acquisition really diminishing - or is it even becoming superfluous?

A brief comparison of the systems with regard to the topic of "disaster management" gives a differentiated picture. 
Satellite data have a big advantage - the satellite orbits the earth and can capture virtually any location (or disaster). If it is a satellite family, disasters can be identified very shortly after their occurrence and measures to save human lives can be supported at short notice. There are already many examples of this, including earthquake disasters and floods. On the other hand, there are serious disadvantages - you fly above the cloud cover, which optical sensors cannot penetrate. Another disadvantage is the geometric resolution. A high resolution (currently $30 \mathrm{~cm}$ ) is very expensive due to the commercialization of satellite remote sensing. With its Copernicus program, the European Union offers an important alternative - the data are free of charge, but currently with resolutions of 10 meters at Sentinel-2. Relatively low flying drones seem to be the solution to capture the extent of a disaster with high detailing. The current development of the drones and their sensors is breathtaking. Optical sensors, laser scanners and hyperspectral technology mounted on drones allow the highest resolutions and accuracies. There are now so many providers of the most diverse technical designs of drones that geo-exhibitions (such as Intergeo in Germany) effortlessly fill a large hall exclusively with drones.

However, there are clear limits to the use of drones in disaster situations. On the one hand, the systems in question are classified as "aircraft" and are thus subject to the requirements of the authorities for flight safety as well as aircraft (application for a permit to fly, etc.). Furthermore, there are national regulations for the operation of drones. In Germany, for example, it is not permitted to operate drones outside the field of vision of the drone pilot. This significantly limits the coverage of larger areas. In any case, there are clear limits to the use of drones in large disaster areas (e.g. floods); the high time and personnel requirements also lead to high costs. Satellite data and the use of drones therefore have many advantages for the collection of geodata in the event of a disaster - but also very clear disadvantages. Ultimately, the type, location and extent of the disaster will determine which data is required. This dialectic of advantages and disadvantages naturally also applies to the airborne acquisition of geodata. However, there are a strikingly large number of applications where the most valuable information for coping with disasters is provided by aircraft. From flight altitudes between approx. 200-800 meters the necessary information can be obtained quickly, comprehensively and up-to-date with a good accuracy. This compensates for some disadvantages, such as the relatively high costs. And, unfortunately, crossborder operations are still very difficult due to the different legislation and the associated difficulties in obtaining a permit to fly in a neighbouring country. Three very different examples will be used in the following to demonstrate how airborne remote sensing can achieve optimum results in disaster situations.

\section{FLOODS AT RIVERS}

In 2013 there was an extreme flood event on one of the largest German rivers - the Elbe. Caused by heavy rainfall in the Czech Republic followed by flooding in the Czech Republic, the peak of the flood reached Germany at the beginning of June and moved to Hamburg within a few days only. Large areas along the Elbe, Saale and Mulde rivers were flooded. An impression is given by figure 3.

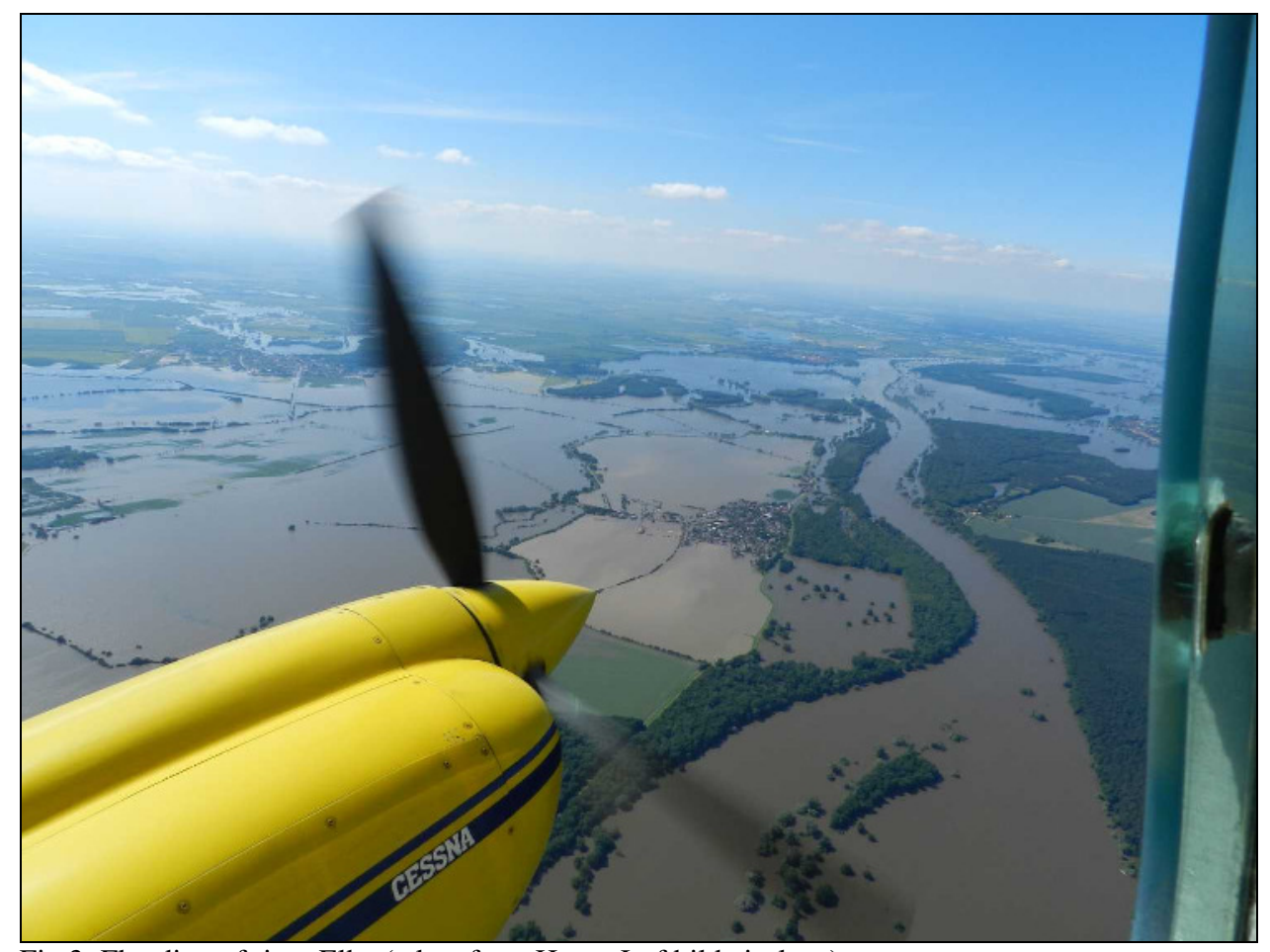

Fig 3: Flooding of river Elbe (taken from Hansa Luftbild airplane)

Hansa Luftbild received the demanding order to record this damage event by means of aerial photographs. The decisive challenge was to capture the pictures with a geometric resolution of $10 \mathrm{~cm}$. At the same time, the images should always be taken at the peak of the tidal wave. This set a very narrow time window, i.e. in view of the - of course - bad weather it was necessary to fly below the cloud cover. 
The task could be solved by using a camera DMC-1 (Zeiss/Intergraph; now Hexagon) mounted on a twinengine Cessna-404. In order to achieve a GSD of $10 \mathrm{~cm}$ with this camera, a flight altitude of 1000 meters above ground must be maintained - so that one could mostly stay under the clouds.

The flood area was huge and stretched from the GermanCzech border South of Dresden to shortly before Hamburg, supplemented by the floods of the tributaries Saale and Mulde. The total length was 983 river kilometres and the area 2,471 square kilometres. 16,693 coloured aerial photos were taken.

$\begin{array}{ccl}\text { date } & \text { photos } & \text { region } \\ 05.06 .2013 & 2.952 & \text { River Mulde } \\ 06.06 .2013 & 1.510 & \text { River Saale North } \\ 07.06 .2013 & 3.086 & \text { River Saale South } \\ 07.06 .2013 & 1.922 & \text { River Elbe South } \\ 08.06 .2013 & 591 & \text { River Elbe South } \\ 09.06 .2013 & 2.992 & \text { Elbe and Rosenburg } \\ 10.06 .2013 & 1.087 & \text { Elbe to Wittenberge } \\ 11.06 .2013 & 1.988 & \text { Elbe and Fischbeck } \\ 12.06 .2013 & 5.65 & \text { River Elbe North } \\ & 16.693 & \end{array}$

Table 1: Project timeline

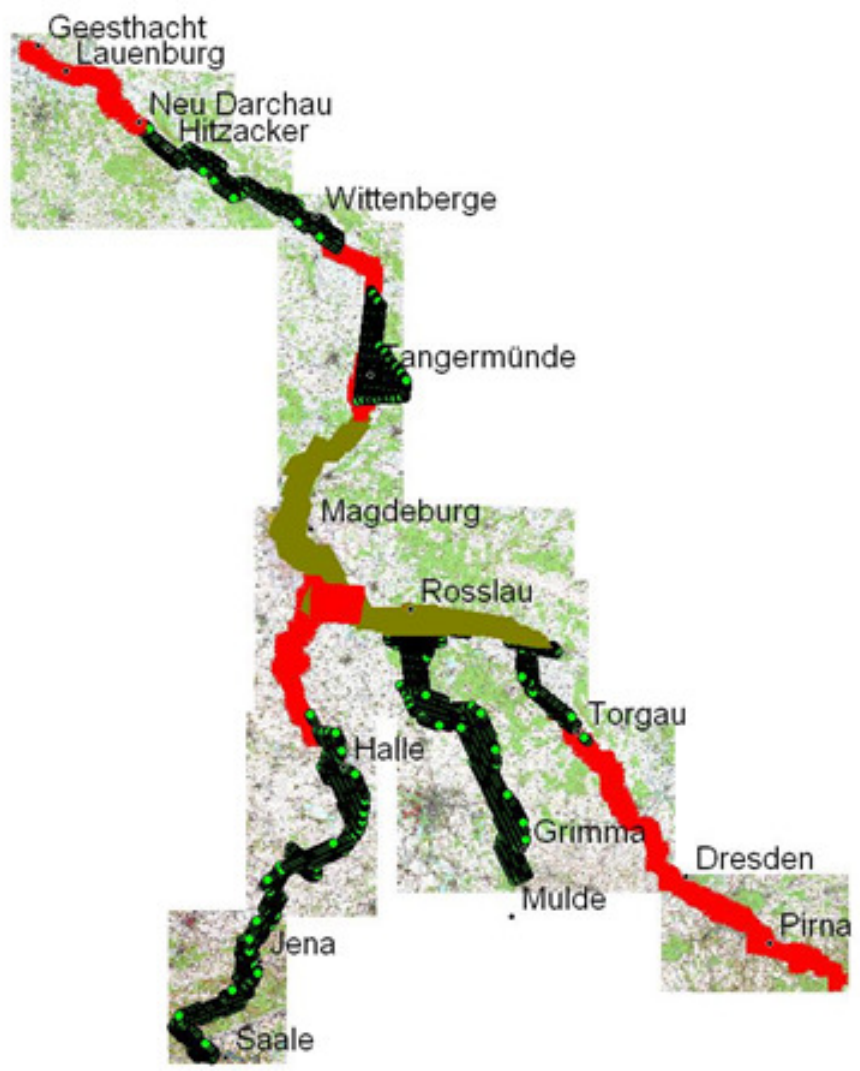

Fig 5: Project area Elbe, Saale and Mulde

The situation was aggravated by two severe dam breaches (Rosenburg and Fischbeck) during the project. Here the flight planning had to be changed very quickly so that the new areas could be recorded at short notice.

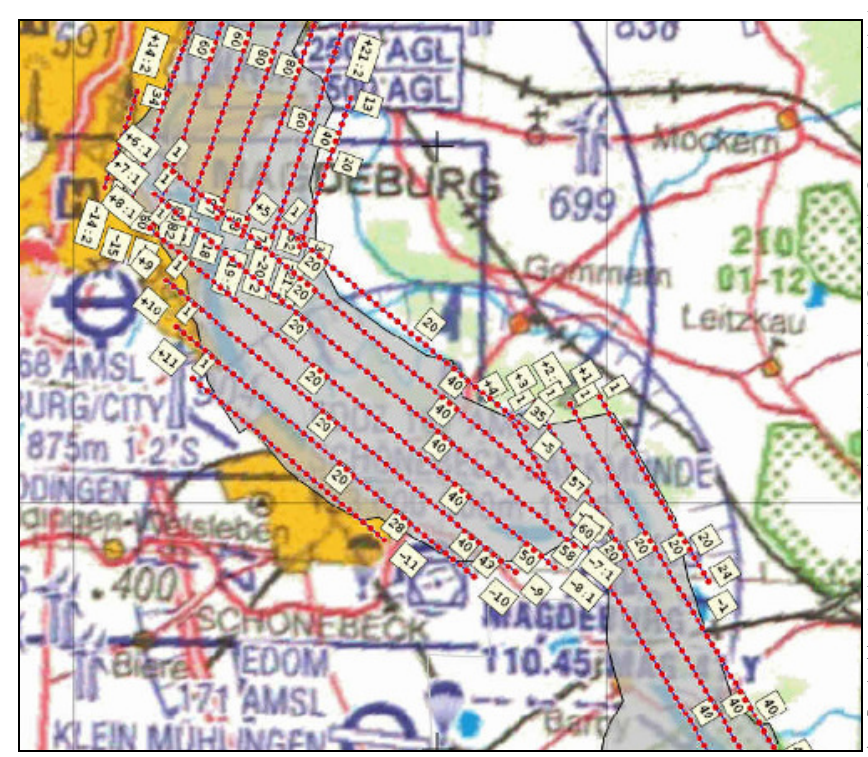

Of course the flood was also observed by various

satellites, but optical data with $10 \mathrm{~cm}$ resolution below the cloud cover could not be obtained. And for a drone mission the area was simply much too large.

Image data could thus be obtained under very difficult conditions - but the decisive factor is how this information was used for disaster management. For example, Hansa Luftbild was able to participate in follow-up projects in which the aerial photographs were used to precisely define the water-land boundary. In this way, the aerial photographs served to settle claims for damages by insurance companies.

But far more important are the hints for the planning of new protective measures (raising the dike by identifying weak points in the dike system, designating polder areas, renaturing water bodies, improving the safety of fuel oil tanks, etc.).

The evaluation of the data also served to improve crossborder flood risk management (in this case in particular the cooperation of German and Czech authorities).

\section{URBAN FLASH FLOODS}

The second example of airborne disaster management also has something to do with "too much water", but it does not announce itself several days before as in the first example. In the case of so-called urban flash floods (or heavy rainfall events), water comes out of the clouds in extreme quantities without prior notice. Climate change means that we increasingly have short, extreme weather events - including flash floods of this kind. Cellars and underground garages that are full to capacity with rain 
water are very annoying, but in some cases there is also danger to life and limb.

It is impossible to record such events by satellite, airplane or drone, because the event often lasts only a few hours or less. The damage, on the other hand, is enormous, especially of course if the area is inhabited. Subsequent damage mapping is of course feasible with remote sensing. The better way, however, is to provide the appropriate geoinformation for damage prevention or at least damage limitation. This enables local authorities to prepare for such events.

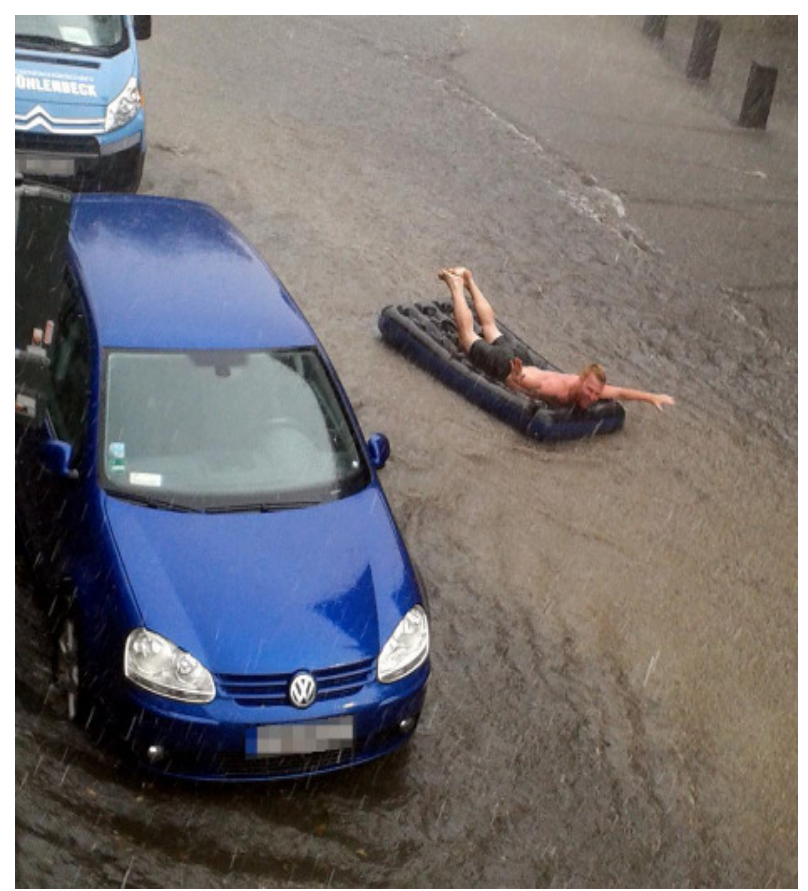

Fig 6: Urban Flash Flood in Münster city

(Source: dpa/cas fdt)

The key questions with this problem are "Where does the water flow to?" and "Where does it damage?". This requires a local, detailed model-based investigation. Such a simulation requires good input data. Some of these data should be available in every municipality (building stock,
In Germany there are already the first municipalities that use geodata for protection against urban flash floods. Not only because they are legally obliged to take precautions, but also because many municipalities have already had negative experiences. This includes Münster, Hansa Luftbild's home town (see Figure 6).

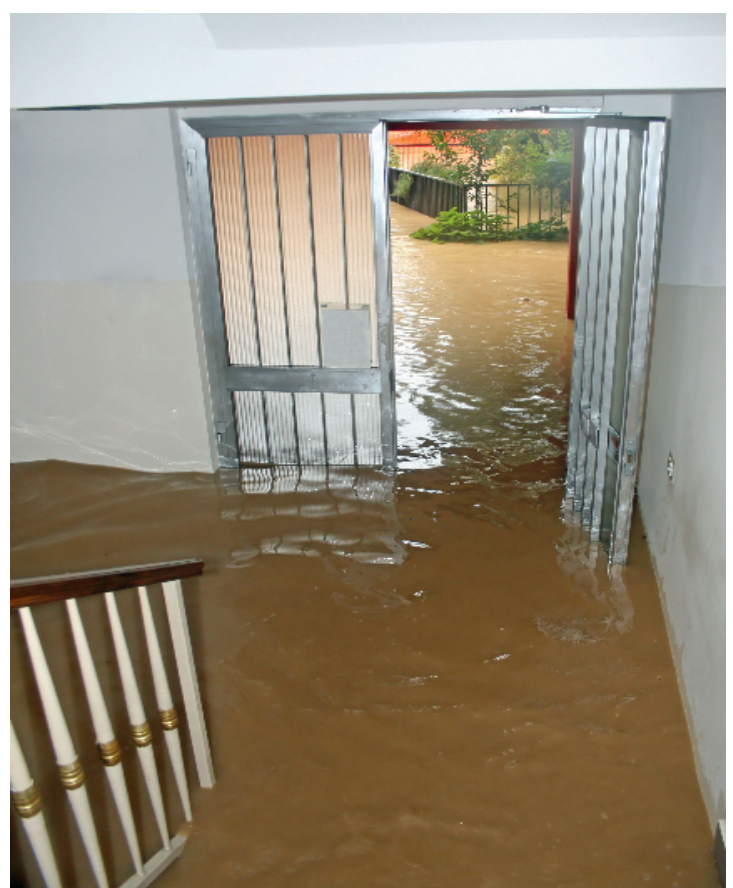

Fig 7: Urban Flash Flood,

Water in a private house

sewer data, etc.). Other data are not available or of insufficient quality (elevation model, break lines, etc.).

Figure 8 shows a section of a medium-sized city on the edge of the Black Forest, which was flown by Hansa Luftbild in spring 2019 (GSD 5cm, overlaps 60\%/50\%). 


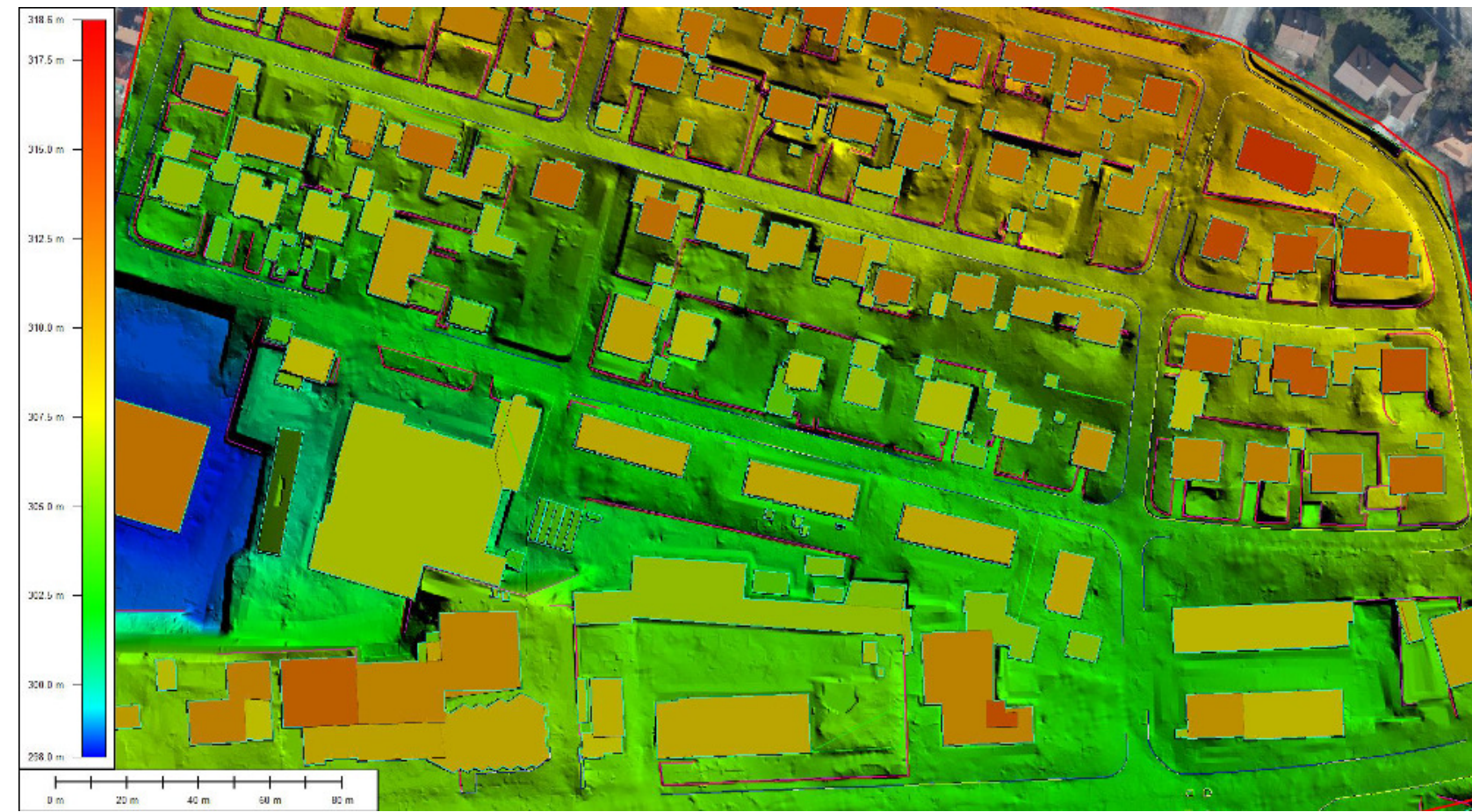

Fig 8: Basic image for a risk map

A digital elevation model (DEM) was generated by a matching process of the aerial photographs. One can clearly see that the terrain in the upper part of the image (North) is higher, so the water will mainly flow from North to South. However, break lines were also measured. These show that the water is dammed at the upper light green east-west road and forced in certain directions. South of this road there are dark green areas which represent depressions and thus collect the water. The residential buildings located there are very susceptible to flooding. If there is also a kindergarten underneath, the situation may become dramatic.

It is therefore necessary to provide precise data on the possible flow paths of the water (i.e. also the height of the kerbs, the location of each gully, and the detection of each obstacle).

In addition to the data on the urban sewerage system, this is all important input information for a hydraulic simulation. There are numerous commercial programs for this and there are specialized companies with which Hansa Luftbild cooperates.

Finally, it is about the production of hazard maps or risk maps of an urban area, which provide vital information for urban planning, urban drainage, disaster control and the public. The data can be used to prevent heavy rainfall, e.g. by

- construction of drainage ditches and rainwater retention basins

- unsealing of surfaces or replacement by waterpermeable surface coverings

- erection of obstacles (walls) to force flowing water in directions

- roof greenings

- keeping areas free for natural infiltration, creating green areas
Danger of urban flash floods is real and one has to prepare the protection from them seriously. Good simulation programs also require good geodata as a basis. Airborne remote sensing - and apparently only this - can provide the required accurate geodata.

\section{FOREST DAMAGE CAUSED BY BARK BEETLES}

Drought and pest infestation have dramatically worsened the condition of our forests in recent years. In addition, there were storms such as the recent storm "Eberhard". There is no doubt that global climate change is also increasingly causing extreme weather events that damage forests, to which forest administrations and forest owners must respond.

Above all, special attention must urgently be paid to the rampant bark beetle infestation in order to prevent or at least limit its further spread. This requires an up-to-date knowledge of the affected areas, ideally early detection. The known forest methods (visual terrestrial observation by forest specialists, pheromone traps, etc.) are currently reaching their limits and should be supplemented by detailed information from the air.

The basic advantages of remote sensing become clearly visible - namely to provide data up-to-date, fast and homogenously area-wide.

Airborne remote sensing can primarily offer visible and near infrared airborne surveys. For special applications the "Airborne Laser Scanning" and the hyperspectral flights or a combination of these data is useful. In the summer of 2018 Hansa Luftbild was asked to carry out a project for the State enterprise "Sachsenforst", in which the National Park "Saxon Switzerland" at the German-Czech border was captured using aerial photos $(10 \mathrm{~cm}$ pixels) and digital orthophotos were produced. The purpose of this inventory was to identify forest areas damaged by the bark beetle. 


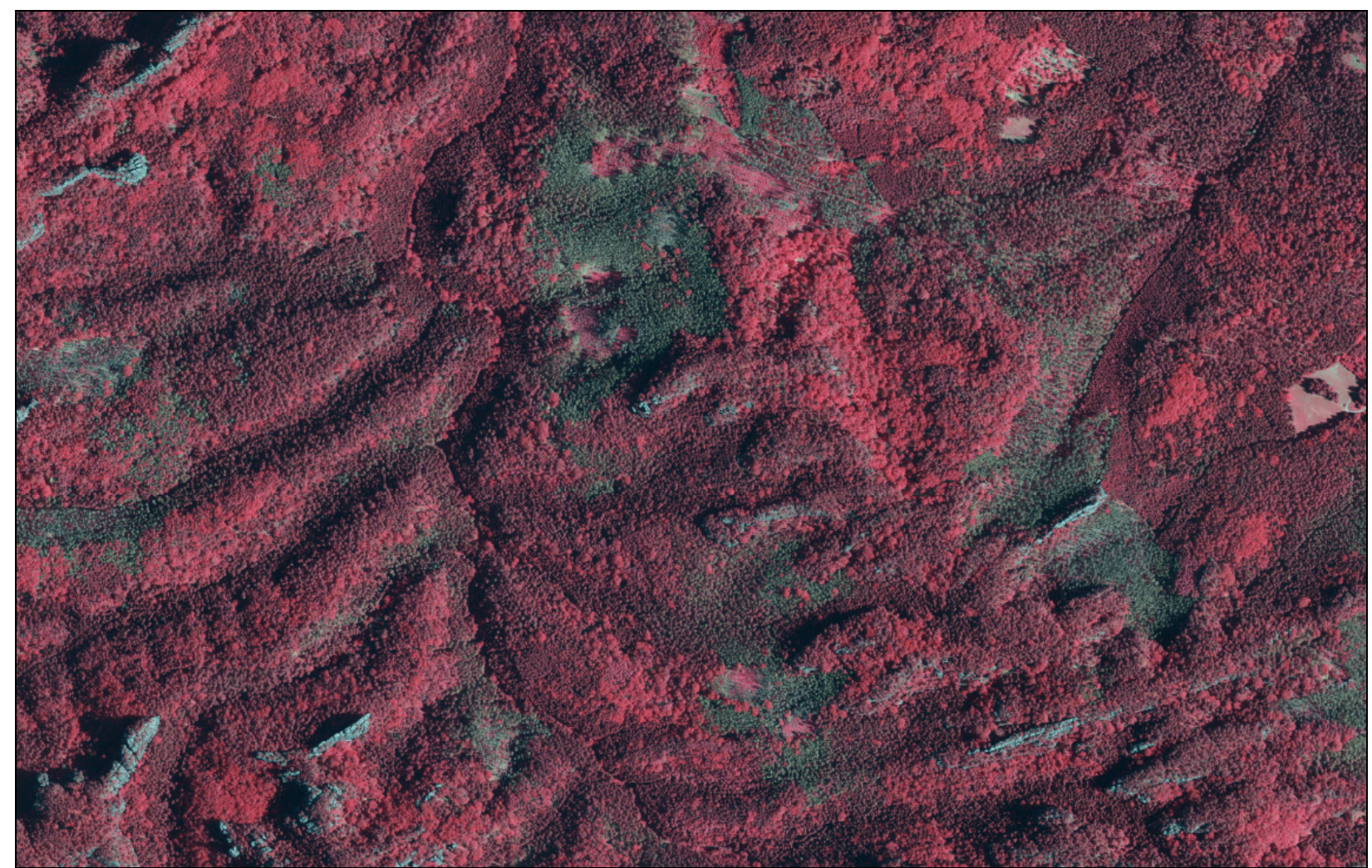

Fig 9: Ortho photo National Park „Sächsische Schweiz", obtained and processed by Hansa Luftbild (reddish: healthy stands; grey: infested stands)

As the photo shows, such areas can be well delimited by means of visual control. Of course, typical signs of infestation, such as drilling dust at the base of the trunk, are not visible in aerial photographs - but crown discoloration and crown thinning indicate the activity of the bark beetle and are clearly visible in the aerial photograph. Particularly in the infrared range (as in the picture above) the damage picture and - with repeated flights - the damage process can be represented well and thus also an early detection is possible. The intersection of these data with existing information in a GIS (forest operation maps, forest type maps, ...) supports semiautomatic screening and infestation detection.

Of course, special flights are correspondingly complex. On the other hand, 100 sqkm of forest with $10 \mathrm{~cm}$ pixels can be captured on a single (cloud-free) day; in the colour and infrared range with the possibility of single tree assessment.

For a good damage mapping, image data with at least $20 \mathrm{~cm}$ resolution are necessary, which again places the airborne remote sensing in the foreground.

However, the big challenge with the problem "bark beetle" is its early detection.
In general, the physiological needle changes during pest infestation are divided into three phases: green, red and grey. Damage in the red phase (visible discoloration of the needles) and in the grey phase (few/no needles and grey trunk) can already be sufficiently detected in the aerial photograph (see above). The focus is on the identification of dead trees and the area-related documentation of damage. However, it is very desirable to enable early detection of bark beetles already in the green phase and thus to allow early human intervention. The transition from the green to the red phase has a very complex background; there is, however, a well-founded assumption that disturbances in the pigment balance are causal and are reflected spectrally. Narrow-band wavelengths (e.g. at $717 \mathrm{~nm}$ ) could support a distinction between "infested" and "uninfected" at an early stage of beetle infestation.

Airborne hyperspectral sensors offer the possibility to detect in such specific wavelengths, but the detection of forest areas is not yet very common. Hansa Luftbild is cooperating with the Hungarian company Envirosense. Initial results give reason to hope that hyper spectroscopy will be used to detect early bark beetle damage. 


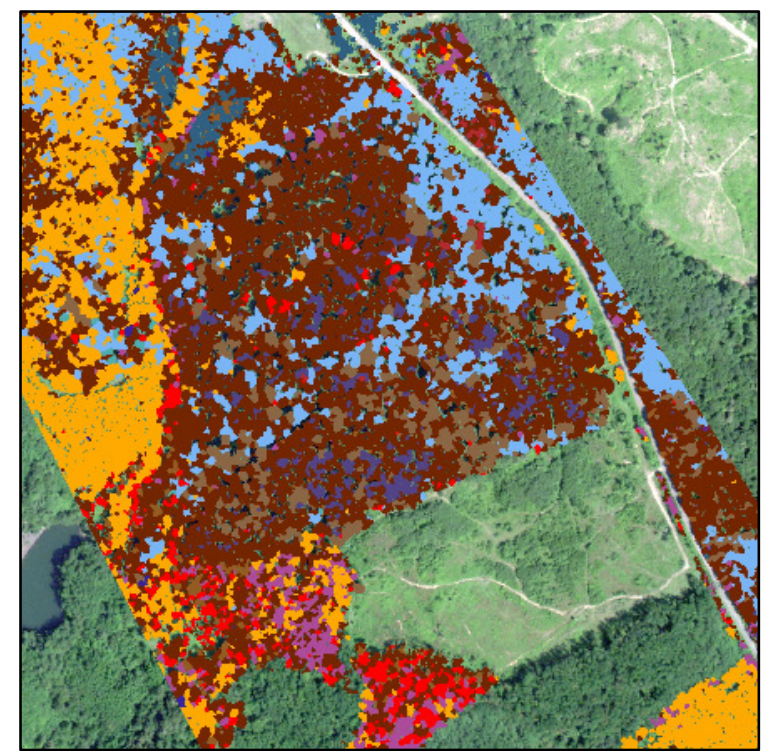

Robinia pseudoacacia

Fagus sylvatica

Ailanthus altissima

Ailanthus altissima (flowery)

Quercus cerris

Prunus avium $\mathrm{L}$.

Tilia tomentosa

Pinus nigra

Carpinus betulus

Quercus robur

Quercus petraea

Picea abies

Quercus pubescens

Larix decidua Mill.

Fraxinus ornus

Fig 10: Differentiation of tree types by means of hyper spectroscopy

Figure 10 shows the result of a combined hyperspectral and laser data evaluation. The images were taken with an AISA Kestrel10 hyperspectral sensor (1.0m ground pixel) and a Leica ALS70 laser system (8 points/sqm). The use of pixel-based and object-based classification programs allowed the production of a tree species map.

This method is currently being further developed in the direction of early detection of forest damage. The

hyperspectral method will certainly receive a boost with the launch of the Copernicus satellite EnMAP next year.

\section{SUMMARY}

Three selected examples showed that airborne technologies make valuable and unique contributions to disaster management.

Despite enormous progress in satellite and drone technology, this will obviously remain the case for many years to come.

\section{ACKNOWLEDGEMENTS}

The author wishes to thank the State enterprise Sachsenforst for the permission to use figure 9. The author also wishes to thank company Envirosense Kft. (Hungary) for the good cooperation and for the permission to use figure 10 . 